кафедрой «Машиноведение», Государственный соизиально-гуманитарный университет. Россия.

140410, г. Коломна, ул. Зеленая, 30.

Тел.: (495) 615-13-30.

Смирнов Алексей Игоревич, аспирант кафедры «Технологии металлов и ремонта машин», Рязанский государственный агротехнологический университет имени П.А. Костычева. Россия.

390044, г. Рязань, ул. Костычева, 1.

Тел.: (4912) 35-88-31.

Ключевъе слова: дождевальная машина; энергосиеенные свойства; искусственный дождь; водоподача.

\title{
TRACTIVE CHARACTERISTICS OF MULTI-BASED IRRIGATION MACHINES
}

Ryazantsev Anatoliy Ivanovich, Doctor of Technical Sciences, Professor of the chair "Machine Science", State Social and Humanitarian University. Russia.

Antipov Aleksey Olegovich, Candidate of Technical Sciences, Associate Professor of the chair "General Technical Disciplines, Theory and Methodology of Vocational Education", State Social and Humanitarian University. Russia.

Malko Igor Valeryevich, Candidate of Technical Sciences, Associate Professor of the chair "Machine Science", State Social and Humanitarian University. Russia.

Smirnov Aleksey Igorevich, Post-graduate Student of the chair "Technologies ofMetal and Machine Repair", Ryazan State Agrotechnological University named after P.A. Kostychev. Russia.

Keywords: irrigation machine; energy-connecting qualities; artificial rain; water supply.
It is noted, that optimization of parameters of working system of multi-based irrigation machines "Fregat" and "Kuban-LK1" is based on studying the system "rainsurface-DM", inferencing indexes of energy-connecting car qualities. Questions of influence of the degree and height of soil-connections on the underlined characteristics are discussed. The data of laboratory researches is presented, that let judge about practical absence of soil sticking on tires by means of powerful washing by artificial rain. It is stated that irrigation - machines provide necessary energy - connecting qualities in the whole range is irrigation norms. Their increase is observed in cases of elevated water supply (400 $\mathrm{m}^{3} / \mathrm{ga}$ and more) and in cases of changing the direction and height of soil - connections.

\section{ОПРЕДЕЛЕНИЕ ОПТИМАЛЬНОГО СООТНОШЕНИЯ СКОРОСТЕЙ РАБОЧИХ ЭЛЕМЕНТОВ МАШИН ПРИ УБОРКЕ АРБУЗОВ И КАПУСТЫ}

\author{
ЦЕПЛЯЕВ Алексей Николаевич, Волгоградский государственный аграрный университет \\ УльЯНОВ Максим Владимирович, Волгоградский государственный аграрный университет \\ ЦЕПЛЯЕВ Алексей Витальевич, Волгоградский государственный аграрный университет \\ КЛИМОВ Сергей Анатольевич, Волгоградский государственный аграрный университет \\ ЦЕПЛЯЕВ Виталий Алексеевич, Волгоградский государственный аграрный университет
}

В статъе рассматриваются результаты проведения опытов по определению соотночения скоростей движущихся элементов рабочих органов при уборке арбузов или кочанов капусты, имеющих форму, близкую к сферическому телу. Выявлено, ито транспортерный комбайн для уборки арбузов, снабженный активным вкатывателем, способен защемлять плоды между транспортером и лентой вкатывателя, ито приводит к повреждению плодов. Для нахождения минимального допустимого повреждения (до 5 \% согласно агротребованиям) необходимо, чтобы лента вкатывателя выполняласъ из резинового полотна с коэффициентом трения $f_{\mathrm{r}}=0,48$, пределы изменения от 1,0 до 1,3, размеры плодов $d_{\text {min }}=15$ см, $d_{\text {max }}=30 \mathrm{cM.}$

Введение. Операции по уборке арбузов и капусты в технологическом процессе возделывания и уборки бахчевых и овощных культур до сих пор низкомеханизированы [4]. Плоды арбузов, как и кочаны капусты, имея достаточно большую массу, чувствительны к механическому воздействию рабочих органов машин. Поэтому в конструкциях комбайнов для уборки продукции предусмотрены рабочие органы с одновременно движущимися элементами, которые защемляют плоды и подают их на элеваторы [2]. Определение их конструкторских и кинематических параметров, снижающих повреждение плодов, остается весьма актуальным. В соответствии с агротребованями повреждение плодов и кочанов капусты при уборке комбайнами не должно превышать 5 \%. Значение этих показателей существенно снижаются за счет правильного подбора материалов рабочих органов, соотношения скоростей их подвижных элементов при уборке с учетом размеров плодов и кочанов [5].

Цель исследования - определить параметры соотношения скоростей рабочих элементов бахче- и капустоуборочных комбайнов, влияющих на повреждение плодов арбузов и кочанов капусты; производительность комбайнов в зави- 
симости от коэффициентов трения поверхностей рабочих элементов.

Методика исследований. Трение покоя, качения и скольжения плодов арбузов и кочанов капусты определяли на специальных приборах [7].

Исследование кинематических параметров подбирающих устройств комбайнов проводили на специальной лабораторной установке в почвенном канале ВолГАУ. Установка включала в себя подвижную тележку, на которой монтировали по два рабочих элемента устройств, имитирующих работу подборщиков комбайнов. Кинематические режимы рабочих элементов изменялись независимо друг от друга. Каждый опыт проводили в пятикратной повторности, последующую математическую обработку результатов проводили по методике Г.В. Веденяпина [1].

Результаты исследований. Наиболее трудоемким процессом при возделывании бахчевых и овощных культур является уборка. Плоды бахчевых и овощных, близких им по форме, имеют достаточно большую массу, при этом чувствительны к механическому воздействию. Для примера рассматриваются плоды арбузов, имеющих сферическую форму, из овощных - кочаны капусты.

Механическая уборка таких плодов связана обычно с движущимися частями рабочих органов машин. При этом одни элементы рабочего органа перемещаются относительно других и достаточно часто с разными скоростями. К ним относятся машины шнекового, транспортерного, накатывающего действия $[9,10]$. Плоды, оказывающиеся в условиях одновременного воздействия двух движущихся с разными скоростями элементов, подвергаются сжатию, истиранию, удару, излому и т.д. Все указанные факторы приводят к внутреннему и наружному повреждению плодов арбузов, отрыву и облому частей кочанов капусты. Такие явления наблюдаются в комбайнах транспортерного типа - для уборки арбузов и в комбайнах шнекового типа - для уборки кочанов капусты [6, 8].

Рассмотрим взаимодействие основного транспортера и ленты активного вкатывателя при попадании между ними плода арбуза [9,10]. Это же условие возможно при уборке капусты шнековым комбайном и попадании кочана капусты между шнеком и вкатывателем [8].

Определим влияние соотношения скоростей при уборке арбузов:

$$
\lambda^{\prime}=\frac{V_{\pi}}{V_{T}^{\prime}}
$$

где $V_{n}$ - скорость перемещения ленты вкатывателя; $V_{\mathrm{T}}$ - скорость движения основного транспортера.
На рис. 1 представлены зависимости, графически описывающие соотношение скоростей при различных коэффициентах трения $\left(f_{\mathrm{T}}\right)$. С ростом $\lambda^{\prime}$, согласно графику, доля защемленных плодов уменьшается. Показатель защемления зависит от коэффициента трения плодов о поверхность ленты вкатывателя. Так, лента вкатывателя из резинового полотна (РП) $\left(f_{\mathrm{T}}=0,61\right)$ при соотношении скоростей с транспортером $\lambda^{\prime}=0,75$ приводит к защемлению $\delta^{\prime}=11 \%$, а для ленты с резинотканевым полотном (РТК) $\left(f_{\mathrm{T}}=0,45\right)$ при соотношении скоростей $\lambda^{\prime}=0,75$ защемление равно $\delta^{\prime}=8,2 \%$, наименьшее его значение соответствует ленте вкатывателя, выполненной из фторопласта $\left(f_{\mathrm{T}}=0,22\right) \lambda^{\prime}=0,75, \delta^{\prime}=5 \%$. Это объясняется тем, что плоды, транспортируемые лентой с большим коэффициентом трения, перед входом на кожух транспортера испытывают большее воздействие элементов конструкции, что приводит к их повреждению, но при этом следует учитывать, что использование материала вкатывателя с малым $f_{\text {т }}$ приводит к сгруживанию плодов перед кожухом, что затрудняет рабочий процесс уборки. Поэтому последующие исследования проводили для материалов конструкции из резинового полотна (РП) и резино-тканевого полотна (РТК).

Кривые 1, 2 и 3 идентичны, с ростом коэффициента соотношения скоростей количество защемленных плодов уменьшается. Так, увеличение $\lambda^{\prime}$ от 0,5 до 1,0 на графике кривой 3 приводит к уменьшению защемления $\delta^{\prime}$ от 10 до $2 \%$. График, построенный для этих пределов, может быть описан уравнением обратно-пропорциональной зависимости. Увеличение коэффициента $\lambda^{\prime}>1,0$, практически не снижает защемления плодов, что наглядно подтверждается на графиках. Например, для кривой 3 при $\lambda^{\prime}=1,0 \delta^{\prime}=2,0 \%$ и при $\lambda^{\prime}=1,25, \delta^{\prime}=1,5 \%$. Аналогичная тенденция отмечается и для кривых 1, 2. Таким образом, основываясь на вышеуказанных рассуждениях,

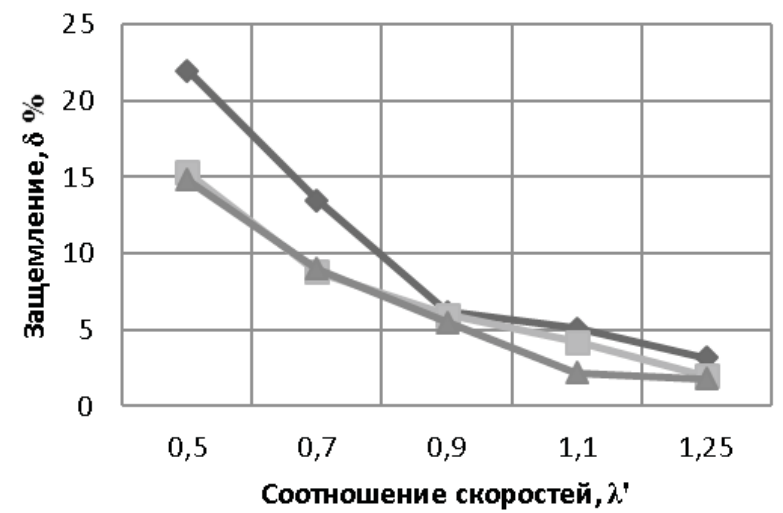

$\leadsto$ Резина (РП) -РТК $\leftarrow$ Фторопласт

Рис. 1. Влияние соотношения скоростей вкатывателя и шнека на защемление плодов 
значениям $\lambda^{\prime}$ от 1,0 до 1,25 соответствует минимальное защемление плодов.

Для определения зависимости усилия защемления плодов от изменения соотношения скоростей проводили опыты по нахождению усилий на плоды при взаимной работе вкатывателя и транспортера.

Согласно опыту, устанавливающему зависимость глубины распространения пластической деформации от усилия защемления, полное исключение возможного внутреннего повреждения плодов и увеличения срока их хранения после механического подбора возможно при статическом усилии сжатия не более $400 \mathrm{H}$ для арбузов и до 500 Н для капусты. При этом пластическая деформация мякоти плода и кочана капусты практически отсутствует.

На графике рис. 2 представлены зависимости усилия замещения от соотношения скоростей: окружной - точек вкатывателя и поступательной движения транспортера.

Для различных сортов арбузов и разных материалов, из которых изготовлена лента вкатывателя, кривые носят различный характер. Например, графики зависимости 1 располагаются несколько выше, чем кривые 2 , а следовательно, и большее усилие защемления возникает при перемещении плодов на тех же скоростях. При этом сорту арбузов Крим-свит соответствует большее усилие защемления, чем сорту Холодок. Такое расположение кривых на графике объясняется различными коэффициентами трения плодов о ленту вкатывателя и индексом формы плодов (отношение высоты плода к ширине), причем больший коэффициент трения и индекс формы увеличивают усилие защемления. Индекс формы для плодов Крим-свит $i=1,32$, а для плодов Холодок $i=1,08$.

По характеру кривые 1,2 монотонно убывающие. Изменение соотношения $\lambda^{\prime}$ от 0,5 до 1,0 вызывает более интенсивное уменьшение усилия

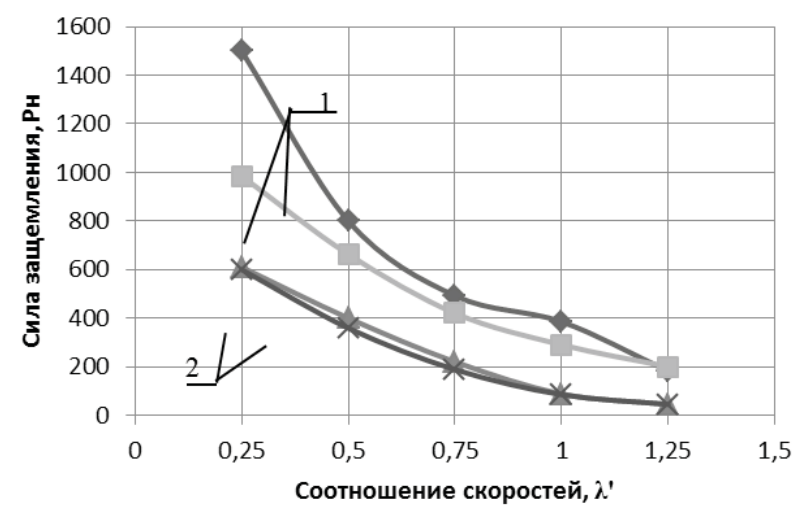

Рис. 2. Зависимость усилия защемления плодов от соотношения скоростей вкатывателя и транспортера: 1 - сорт Крим-свит; 2 -сорт Холодок защемления, чем при $\lambda^{\prime}>1,0$. Так, для сорта «Холодок» зависимость 2 при значении $\lambda^{\prime}=0,75$ приводит к образованию усилия защемления $200 \mathrm{H}$, а при $\lambda^{\prime}=1,0 \quad P=100 \mathrm{H}$, то есть разность усилий $\Delta P$ составляет $100 \mathrm{H}$, но уже при $\lambda^{\prime}=1,25 P=60 \mathrm{H}$, в этом случае $\Delta P$ равно $40 \mathrm{H}$. Отсюда, при соотношении скоростей $\lambda^{\prime}=1,0-1,25$ наблюдается минимальное усилие защемления.

Следовательно, с целью полного исключения повреждения плодов при подаче их на кожух необходимо, чтобы окружная скорость точек вкатывателя была не менее окружной скорости транспортера.

Зависимость времени воздействия от соотношения скоростей. В данном опыте определяли время совместного воздействия транспортера и вкатывателя на плоды бахчевых в зависимости от соотношения скоростей.

Результаты опыта и построенные по ним кривые на графике (рис. 3) позволяют судить о характере изменения времени для различных материалов ленты вкатывателя и сортов арбузов.

Очевидно, при увеличении соотношения скоростей время воздействия на плод уменьшается. Причем для РП ленты значение времени при тех же параметрах аргумента меньше, чем для ленты из РТК. Для ленты из резины указанные сорта арбузов большого влияния на значение времени не оказывают, и характер кривых остается тот же.

На основании полученных результатов в предыдущих опытах оптимальное соотношение скоростей $\lambda^{\prime} \geq 1,0$, на графике этому значению аргумента соответствуют ординаты 0,5...0,75 с для РП и $1,25 \ldots$ 1,5 с для ленты из РТК.

Отсюда следует, что при перемещении плода вкатывателем с резиновым полотном, он меньшее количество времени находится под совместным воздействием вкатывателя и транспортера, т.е. вероятность его повреждения снижается.

Влияние материала вкатывателя на технологический проиесс подбора плодов. Как отмечалось ранее, в точке контакта плода с поверхностью
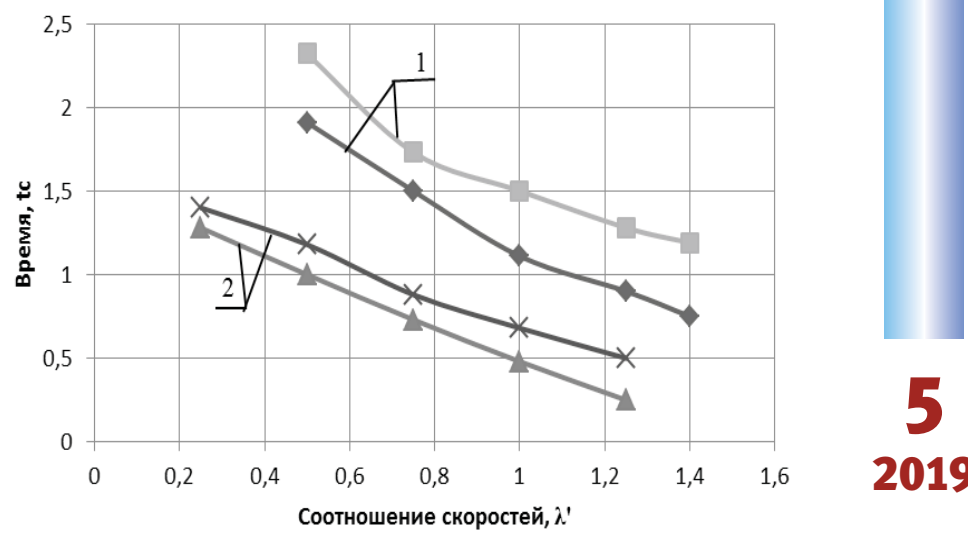

Рис. 3. Зависимость времени воздействия на плоды от соотношения скоростей вкатывателя и транспортера: 1 - сорт Крим-свит; 2 - сорт Холодок 
вкатывателя возникает сила трения, направленная в сторону противоположную перемещению плодов.

Задачей данного опыта было выявить степень влияния коэффициента трения скольжения на производительность комбайна при оптимальных режимах его работы.

Результаты опыта представлены в таблице. При проведении опыта контролировали число плодов, транспортируемых одновременно. Наибольшее количество плодов за один оборот подается лентой вкатывателя из резинового полотна, а коэффициент трения скольжения при этом в 1,3 раза больше, чем полотна из РТК. Сорт арбузов особого влияния на работу вкатывателя не оказывает, т.к. значения количества подаваемых вкатывателем плодов одинаковые и для сортов Холодок и Крим-свит.

Влияние плотности валка на технологические показатели комбайнов. Работу комбайнов для уборки бахчевых культур, согласно аг- ротребованиям, оценивают обычно двумя показателями: поврежденностью плодов и производительностью машины. При этом первый показатель является наиболее значимым, так как повреждаемость бахчевых при подборе не должна превышать 5 \%, включая плоды и кочаны, оставленные на поле. Кроме того, учитывая данные опытов, проведенных в этой и других подобных работах, установлено, что даже незначительные механические повреждения плодов резко ухудшают вкусовые качества, снижают срок хранения, особенно для кочанов капусты.

Изменение повреждаемости плодов в зависимости от плотности валка и скорости агрегата или шага посадки капусты. Настоящим опытом необходимо было установить влияние скорости движения агрегата и количества плодов или кочанов в рядке на одном метре пути (плотности валка или посадки капусты) на повреждаемость и производительность [3].

Определение количества одновременно транспортируемых плодов при оптимальных кинематических характеристиках

\begin{tabular}{|c|c|c|c|c|c|c|}
\hline $\begin{array}{c}\text { № } \\
\text { опыта }\end{array}$ & $\begin{array}{c}\text { Материал } \\
\text { полотна } \\
\text { вкатывателя }\end{array}$ & $\begin{array}{l}\text { Коэффициент } \\
\text { трения } \\
\text { скольжения } f\end{array}$ & $\begin{array}{l}\text { Оптимальное } \\
\text { соотношение } \\
\text { скоростей } \lambda\end{array}$ & Сорт арбузов & $\begin{array}{c}\text { Средняя } \\
\text { масса плодов } \\
m, \text { кг }\end{array}$ & $\begin{array}{c}\text { Количество плодов, } \\
\text { транспортируемых } \\
\text { одновременно }\end{array}$ \\
\hline 1 & РП & 0,44 & 0,535 & Холодок & 3,8 & 3 \\
\hline 2 & & & & & 4,2 & 3 \\
\hline 3 & & & & & 4,0 & 4 \\
\hline 4 & & & & & 3,9 & 3 \\
\hline 5 & & 0,48 & 0,535 & Крим-свит & 4,5 & 4 \\
\hline$\overline{\mathbf{x}}=3,3$ & $\sigma=0,21$ & $m=0,04$ & $P=1,2 \%$ & & & \\
\hline 1 & РТК & 0,311 & 0,323 & Холодок & 4,0 & 2 \\
\hline 2 & & & & & 4,0 & 2 \\
\hline 3 & & & & & 3,9 & 1 \\
\hline 4 & & & & & 3,8 & 2 \\
\hline 5 & & 0,345 & 0,323 & Крим-свит & 4,0 & 2 \\
\hline
\end{tabular}




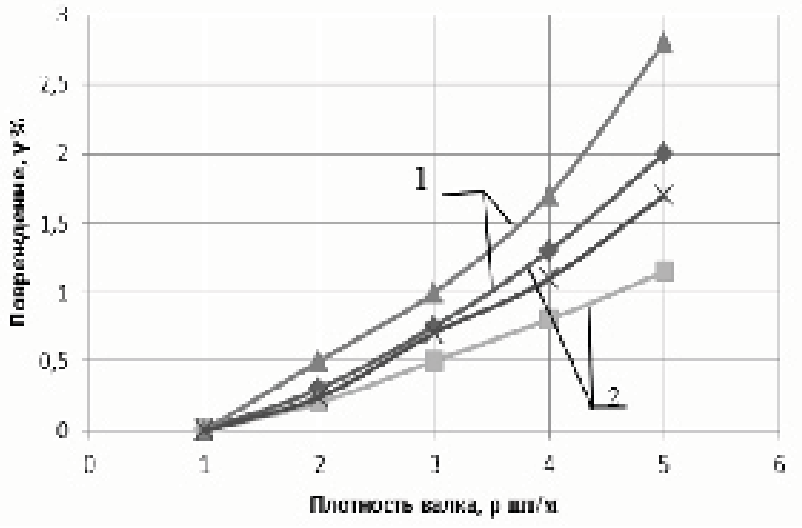

Рис. 4. Зависимость плотности валка на повреждаемость: 1 - зазор между движущимися элементами $\Delta l=150$ мм; 2 - зазор между движущимися элементами $\Delta l=250$ мм

Полученные и представленные на рис. 4 графические зависимости определяли для плодов бахчевых как наиболее чувствительных к механическим воздействиям. Для кочанов капусты повреждаемость в $1,5-1,7$ раза меньше при тех же значениях шага посадки капусты. По экспериментальным результатам и на графиках рис. 4 выявлено, что повреждаемость зависит от плотности. Она выражается на графике кривыми 1 и 2, построенными для скоростей движения агрегата $V_{\mathrm{a}}=0,432 \mathrm{M} / \mathrm{c}$ и $V_{\mathrm{a}}=0,845 \mathrm{~m} / \mathrm{c}, \lambda_{1}^{\prime}=1,0, \lambda_{2}^{\prime}=1,25$ соответственно. Кривая 1 располагается несколько ниже, чем кривая 2, т.е. одинаковому значению аргумента (плотности валка) соответствуют различные значения функции (повреждаемости), например, при плотности $\rho=4$ шт./м для 1 -й кривой $v=1,0$, а для 2-й $v=1,5$.

Как видно из графиков, рост плотности валка еще больше увеличивает разницу повреждаемости. Это связано с тем, что при меньшем зазоре мелкие плоды $(d=15 \mathrm{~cm})$ не остаются на поле, а повреждаются плоды более крупные, несмотря

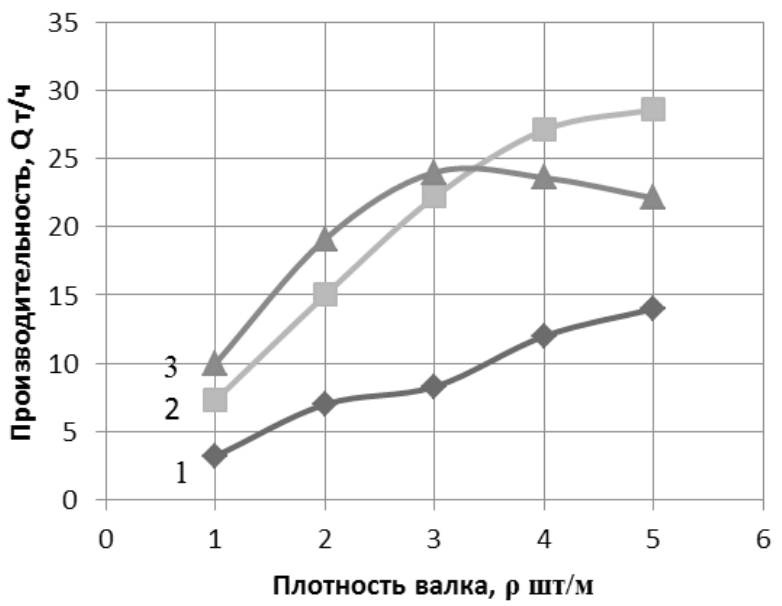

Рис. 5. Влияние плотности валка на технологическую производительность: 1 - скорость $V_{a}=0,4 \mathrm{M} / \mathrm{c}$; 2 - скорость $V_{a}=0,8 \mathrm{M} / \mathrm{c} ; 3$ - скорость $V_{a}=2 \mathrm{M} / \mathrm{c}$ на то, что в конструкции предусмотрен механизм отвода вкатывателя при больших нагрузках. Но, учитывая, что агротребования на подборщики допускают повреждаемость до 5 \%, становится возможной работа машины на повышенной скорости и при большем зазоре, которой соответствует кривая 2. Анализируя график 2 , приходим к выводу, что его функция монотонно возрастающая, но в первоначальный момент до плотности $\rho=4$ шт./м увеличение незначительное. Так при $\rho=1$ шт./м $v=0$, а при $\rho=4$ шт./м $v=1 \%$, но уже при $\rho=7$ шт./м $v=4,8 \%$. Это повышение объясняется ухудшением равномерности подачи к транспортеру.

Влияние плотности валка на производительность подборщика. Очевидно, производительность находится в прямопропорциональной зависимости от плотности валка, что установлено по кривым графика рис. 5. Увеличение скорости агрегата $V_{\text {a }}$ также приводит к росту технологической производительности. На представленном графике кривая 1 построена для $V_{\mathrm{a}}=0,432 \mathrm{~m} / \mathrm{c}$, вторая для $V_{\mathrm{a}}=0,845 \mathrm{~m} / \mathrm{c}$, третья для $V_{\mathrm{a}}=1,3 \mathrm{M} / \mathrm{c}$. Нижняя часть графиков $1,2,3$ описывается прямопропорциональной зависимостью. Однако, увеличение плотности валков до 7-8 плодов на 1 м пути вначале приводит к максимальной производительности, а затем и к резкому ее падению.

Согласно ранее проведенному опыту, при плотности $\rho=7-8$ шт./м они не все подаются к зоне приема на транспортер, часть из них, захватываясь вкатывателем, повреждается, а остальные не могут подаваться на транспортер из-за сгруживания. Все это приводит к нарушению технологического процесса, потери большой части урожая, снижению производительности.

Заключение. По результатам выполненных исследований необходимо отметить, что материал полотна вкатывателя является существенным фактором, влияющим на технологические показатели работы комбайна. Согласно проведенным в опыте исследованиям для изготовления полотна вкатывателя должен применяться материал с высоким коэффициентом трения скольжения, например, peзина толщиной не менее 5 мм, что позволяет ей деформироваться и снижать повреждение плодов.

Максимально возможное количество плодов на 1 м пути до 7 шт. как для арбузов, так и для капусты. При этих условиях комбайн в представленном варианте допускает повреждение плодов бахчевых до 5 \%, для кочанов капусты до $3 \%$.

Соотношение скоростей активного вкатывателя и транспортера при уборке арбузов, а также шнека и опорного подвижного катка при уборке 
капусты $\lambda$ ' должно быть больше 1,0. При этом повреждение плодов и кочанов капусты не превышает $5 \%$.

Максимально возможная производительность до 25 т/ч достигается при скорости машины $V_{\text {м }}=0,8 \mathrm{~m} /$ с при повреждаемости $4,5 \%$ для арбузов, 2,5 \% для капусты. Полученные значения не превышают соответствующие показатели агротребований.

\section{СПИСОК ЛИТЕРАТУРЫ}

1. Веденяпин Г.В. Общая методика экспериментального исследования и обработки опытных данных. - М.: Колос, 1973. - 199 с.

2. Комплекс современных модернизированных машин и их рабочих органов для механизации процессов бахчеводства / А.С. Овчинников [и др.]. - Волгоград: Волгоградский ГАУ, 2018. - 228 с.

3. Оценка эффективности развития растениеводства / В.П. Зволинский [и др.] // Известия Нижневолжского агроуниверситетского комплекса: наука и высшее профессиональное образование. - 2017. № 3 (47). - С. 266-274.

4. Создание условий для конвейерного поступления плодов арбуза на продовольственный рынок с целью расширения сроков потребления / Е.С. Таранова [и др.] // Известия Нижневолжского агроуниверситетского комплекса: наука и высшее профессиональное образование. - 2013. - № 3 (31). - С. 103-106.

5. Цепляев А.Н., Китов А.Ю. Физико-механические свойства плодов бахчевых культур // Известия Нижневолжского агроуниверситетского комплекса: наука и высшее профессиональное образование. 2017. - № 3 (47). - C. 216-225.

6. Цепляев А.Н., Шаимов Р.А. Новая капустоуборочная машина // Сельский механизатор. - 2005. № 7. - C. 13-19.

7. Шапров М.Н., Седов А.В. Обоснование конструкции роторного подборщика для уборки плодов бахчевых культур // Известия Нижневолжского агроуниверситетского комплекса: наука и высшее профессиональное образование. - 2013. - № 4 (32). - С. 214-217.
8. Шапров М.Н., Абезин В.Г. Механизированная технология выборочной уборки плодов бахчевых культур // Известия Нижневолжского агроуниверситетского комплекса: наука и высшее профессиональное образование. - 2014. - № 3 (35). - С. 94-96.

9.Zur Anwendbarkeit optimaler Versuchsplane fur die Schatzung einer polynominalen Rergressionsfunktion im Feldversuchswesen. Harpke, Karl. Arch [Текст]. AckerPflanzenbau Bodenkd. - Berlin 34(1990)3. S. 205-212.

10. Zur Bodenstruktur von Hochoder und Schlussfolgerungen zu ihrer Auslastbarkeit durch Wind. Haupt, Rainer. Arch. Acker - Pflanzenbau Bodenkd. Berlin 34(1990)6. S. 393-402.

«Исследование выполнено при финансовой поддержке РФФИ и администращии Волгоградской области в рамках научного проекта № 18-41-340016 18 »

Цепляев Алексей Николаевич, $\partial-p$ c.-x. наук, проф. кафедры «Технические системы в АПК», Волгоградский государственный аграрный университет. Россия.

Ульянов Максим Владимирович, канд. техн. наук, доцент кафедры «Технические системы в АПК», Волгоградский государственный аграрный университет. Россия.

Цепляев Алексей Витальевич, магистрант, Волгоградский государственный аграрный университет. Россия.

Климов Сергей Анатольевич, аспирант кафедры «Технические системы в АПК», Волгоградский государственный аграрный университет. Россия.

Цепляев Виталий Алексеевич, канд. техн. наук, доцент кафедры «Технические системы в АПК», Волгоградский государственный аграрный университет. Россия.

400002, г. Волгоград, просп. Университетский, 26. Тел.: (8442) 41-13-65.

Ключевые слова: соотношение скоростей; лента вкатывателя; плоды арбузов; кочаны капусты; капустоуборочный комбайн; бахчеуборочный комбайн; повреждение плодов; повреждение кочанов.

\section{DETERMINATION OF MACHINES WORKING ELEMENTS SPEEDS OPTIMAL CORRELATION WHEN WATERMELONS AND CABBAGES HARVESTING}

Tseplyaev Aleksey Nikolayevich, Doctor of Agricultural Sciences, Professor of the chair "Technical Systems in Agro-industrial Complex", Volgograd State Agrarian University. Russia.

Ulyanov Maxim Vladimirovitch, Candidate of Technical Sciences, Associate Professor of the chair "Technical Systems in Agro-industrial Complex”, Volgograd State Agrarian University. Russia.

Tseplyaev Aleksey Vitalievich, Magistrandt, Volgograd State Agrarian University. Russia.

Klimov Sergey Anatolyevich, Post-graduate Student of the chair "Technical Systems in Agro-industrial Complex", Volgograd State Agrarian University. Russia.

Tseplyaev Vitaliy Alekseevich, Candidate of Technical Sciences, Associate Professor of the chair "Technical Systems in Agro-industrial Complex”, Volgograd State Agrarian University. Russia.
Keywords: speeds correlation; a roll-in tape; watermelons fruits; cabbage heads; cabbage harvester; melon harvester; fruit damage; cabbage heads damage.

In this article, the authors discuss the results of experiments to determine the working bodies moving elements speeds ratio when harvesting watermelons or cabbage heads, having a shape close to a spherical body. It was revealed that the conveyor harvester for watermelons harvesting, equipped with an active roll-in machine, can jam the fruit between the conveyor belt and the roll-in belt, this leads to the fruit damage. To find the minimum allowable damage level (up to 5\% according to the agrotechnical requirements), it is necessary that the roll-in tape is made of rubber cloth with a friction coefficient of $f_{m}=0.48$, the limits of change are from 1.0 to 1.3 , fruit size is $d_{\min }=15 \mathrm{~cm}, d_{\max }=30 \mathrm{~cm}$. 